\title{
Power Quality Improvement Using Hybrid Passive Filter Configuration for Wind Energy Systems
}

\author{
O. Fatih Kececioglu*, Hakan Acikgoz**, Ceyhun Yildiz*, Ahmet Gani* \\ and Mustafa Sekkeli ${ }^{\dagger}$
}

\begin{abstract}
Wind energy conversion systems (WECS) which consist of wind turbines with permanent magnet synchronous generator (PMSG) and full-power converters have become widespread in the field of renewable power systems. Generally, conventional diode bridge rectifiers have used to obtain a constant DC bus voltage from output of PMSG based wind generator. In recent years, together advanced power electronics technology, Pulse Width Modulation (PWM) rectifiers have used in WECS. PWM rectifiers are used in many applications thanks to their characteristics such as high power factor and low harmonic distortion. In general, L, LC and LCL-type filter configurations are used in these rectifiers. These filter configurations are not exactly compensate current and voltage harmonics. This study proposes a hybrid passive filter configuration for PWM rectifiers instead of existing filters. The performance of hybrid passive filter was tested via MATLAB/Simulink environment under various operational conditions and was compared with LCL filter structure. In addition, neuro-fuzzy controller (NFC) was preferred to increase the performance of PWM rectifier in DC bus voltage control against disturbances because of its robust and nonlinear structure. The study demonstrates that the hybrid passive filter configuration proposed in this study successfully compensates current and voltage harmonics, and improves total harmonic distortion and true power factor.
\end{abstract}

Keywords: Wind energy, Power quality, PWM rectifier, WECS

\section{Introduction}

The energy demand of the world is rapidly increasing due to the rapid growth in population, urbanization and industrialization. The interest of renewable energy sources are much more widespread than in the past due to declining of oil and gas reserves in the world. Wind energy is one of fastest growing renewable energy resources in the world. Use of Wind Energy Conversion Systems (WECS) increases the power quality and stability issues in the power systems. The WECS are consist of variable-speed wind turbine, mechanical drive train, PMSG and AC-DC, DC-AC power converters [1-4]. WECS require power converters for achieving maximum power from the wind turbine and to generate quality power with stability. PMSG is preferred for small wind power generation less than $100 \mathrm{~kW}$, because of its reliability, high efficiency and low cost. AC-DC conversion system consists of two stages namely: Diode bridge rectifier and DC-DC boost converter. The system efficiency of PMSG with diode bridge rectifier is low

$\dagger$ Corresponding Author: Dept. of Electrical and Electronics Engineering, Kahramanmaras Sutcu Imam University, Turkey. (msekkeli@ksu.edu.tr)

* Dept. of Electrical and Electronics Engineering, Kahramanmaras Sutcu Imam University, Turkey. (\{fkececioglu, agani, cyildiz\}@ ksu.edu.tr)

** Dept. of Electrical Science, Kilis 7 Aralik University, Turkey. (hakanacikgoz@kilis.edu.tr)

Received: January 3, 2016; Accepted: August 6, 2016 because of higher order current harmonics in source side. To overcome this problem, PWM rectifiers are preferred better solutions to eliminate the harmonics and improve power factor [4-8].

Particularly in the last two decades, PWM rectifiers have been used for $\mathrm{AC} / \mathrm{DC}$ conversion thanks to the developments in the field of power electronics. When compared to conventional phase controlled rectifiers, these rectifiers are known to possess various qualities such as fixed DC bus voltage, rapid dynamic response, high unity power factors, and bidirectional power flow. Therefore, it is used in numerous applications such as high performance AC motor applications, telecommunication systems and wind energy conversion systems [8-10].

Harmonics, which was once caused by transformers and arc welding, have become one of the most common power quality problems today due to widespread use of power electronics based devices. Harmonics of power system cause problems such as losses in the transmission line and low efficiency, noisy and vibrating motor operation, excessive heating in the transformers and reactors, and decreasing reactive power coefficient. Harmonic currents transmitted by the grid may cause non-sinusoidal voltage drop depending on the grid impedance, which results in a decrease in voltage quality at the point of common coupling. This may negatively affect other receivers which is supplied by the same point. International 
standards such as IEEE 519-1992 and EN 61000-3-2 which limit harmonic levels of receivers were published in order to minimize potential negative effects in the grid voltage [11-14]. Harmonics occurring in the power systems may be eliminated thanks to various filtering techniques such as passive, active or hybrid filters. Passive filters are commonly used due to their low installation costs, simple configuration, reactive power compensation and simultaneous harmonic filtering.

A hybrid passive filter was designed for three-phase PWM rectifiers in the present study, and the performance of the filter was tested by modelling and simulation study. PWM rectifiers and their mathematical model are summarized in Section 2. The structure of hybrid passive filter and its design are discussed in Section 3. NFC is designed for PWM based rectifier in Section 4. Simulation results and the performance of the proposed hybrid passive filter are analysed in Section 5.

\section{The Mathematical Modelling of PWM Based Rectifiers for WECS}

The structure of a three-phase bidirectional AC/DC rectifier is given in Fig. 1. Six pieces of semi-conducting switches are needed in this rectifier. In addition, resistance $\left(\mathrm{R}_{\mathrm{s}}\right)$ and inductance $\left(\mathrm{L}_{\mathrm{s}}\right)$ exists at each phase between the rectifier and grid. DC bus capacitor $(C)$ and parallel $\left(\mathrm{R}_{\mathrm{L}}\right)$ load resistance exists in the DC bus [15-16]. In a threephase, balanced and three-wire system, voltage and current equations of a PWM rectifier are obtained as follows:

$$
\begin{aligned}
& {\left[\begin{array}{l}
V_{a} \\
V_{b} \\
V_{c}
\end{array}\right]=R_{s}\left[\begin{array}{c}
I_{a} \\
I_{b} \\
I_{c}
\end{array}\right]+L_{s} \frac{d}{d t}\left[\begin{array}{c}
I_{a} \\
I_{b} \\
I_{c}
\end{array}\right]+\left[\begin{array}{c}
V_{r a} \\
V_{r b} \\
V_{r c}
\end{array}\right]} \\
& C \frac{d V_{d c}}{d t}=S_{a} \cdot I_{a}+S_{b} \cdot I_{b}+S_{c} \cdot I_{c}-I_{d c}
\end{aligned}
$$

where, $L_{s}$ and $R_{s}$ represents grid inductance and resistance, respectively. $V_{a, b, c}$ represents three-phase grid voltage. $I_{a, b, c}$ represents grid phase currents, while $V_{r a}, V_{r b}$ and $V_{r c}$ represent rectifier input voltage. $\mathrm{V}_{\mathrm{ra}}, \mathrm{V}_{\mathrm{rb}}$ and $\mathrm{V}_{\mathrm{rc}}$ are found by turning on and off switching elements in the rectifier

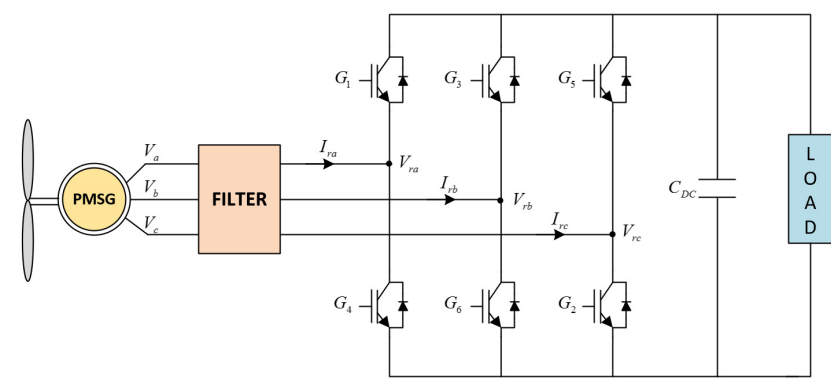

Fig. 1. Configuration of three - phase PWM rectifier for WECS appropriately in order to obtain DC bus voltage. $\mathrm{S}_{\mathrm{a}}, \mathrm{S}_{\mathrm{b}}$ and $\mathrm{S}_{\mathrm{c}}$ represent switching functions. Rectifier phase voltages can be found via the following equation:

$$
\begin{aligned}
& V_{r a n}=\left(2 S_{a}-\left(S_{b}+S_{c}\right)\right) \frac{V_{d c}}{3} \\
& V_{r b n}=\left(2 S_{b}-\left(S_{a}+S_{c}\right)\right) \frac{V_{d c}}{3} \\
& V_{r c n}=\left(2 S_{c}-\left(S_{a}+S_{b}\right)\right) \frac{V_{d c}}{3}
\end{aligned}
$$

In a matrix form, any three-phase electrical quantity in the abc coordinates $\left(\mathrm{X}_{\mathrm{a}, \mathrm{b}, \mathrm{c}}\right)$ can be converted to $\alpha \beta$ coordinates as follows [16-19]:

$$
\left[\begin{array}{l}
x_{\alpha} \\
x_{\beta}
\end{array}\right]=\frac{2}{3}\left[\begin{array}{ccc}
1 & \frac{-1}{2} & \frac{-1}{2} \\
0 & \frac{\sqrt{3}}{2} & \frac{-\sqrt{3}}{2}
\end{array}\right]\left[\begin{array}{l}
x_{a} \\
x_{b} \\
x_{c}
\end{array}\right]
$$

\section{Hybrid Passive Filter Configuration}

Hybrid passive filter is a combination of series and passive filters. The single phase equivalent circuit of hybrid passive filter is shown in Fig. 2.

The series passive filter (SPF) used in the filter configuration is a band-pass filter, while parallel passive filter (PPF) is a band-stop filter. SPF offers low impedance against components in the circuit frequency and high impedance against those in the harmonic frequency. On the other hand, PPF presents high impedance against components in the circuit frequency and low impedance against those in the harmonic frequency. Non-linear loads generate voltage and current harmonics in power systems. These harmonics are prevented from being flow to the grid as voltage harmonics are eliminated on SPF and current harmonics are eliminated on PPF [6-8]. SPF presents high impedance against all harmonic frequencies, thus preventing voltage fed-type harmonics from being transmitted by the load to the grid.

In the fundamental frequency, reactor and capacitor reactances are equal. The value of SPF resonant frequency is assumed close to that of power system frequency. The

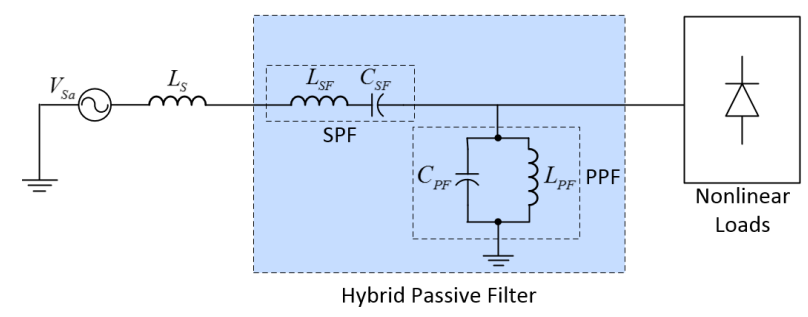

Fig. 2. The single phase equivalent circuit of hybrid passive filter 


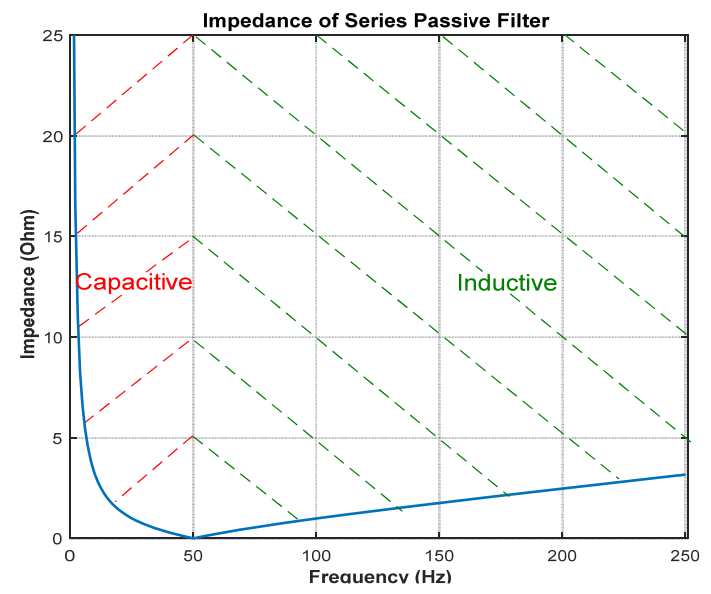

Fig. 3. The frequency response of series passive filter

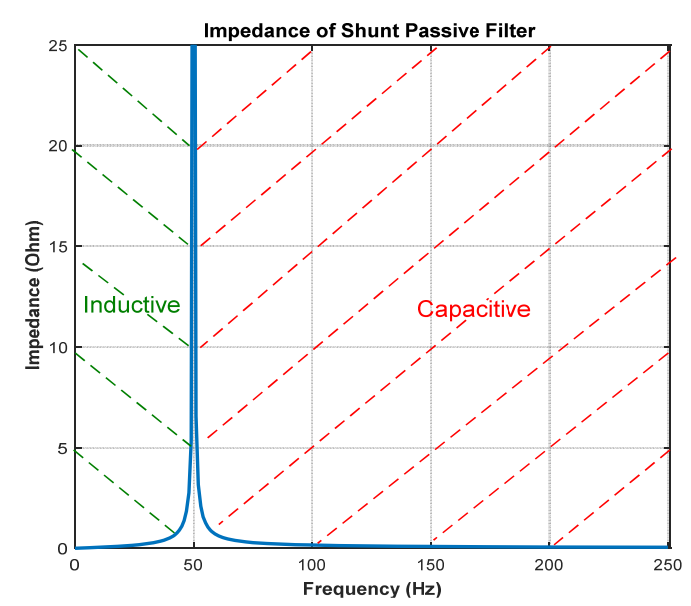

Fig. 4. Frequency response of parallel passive filter

frequency characteristics of series passive filter is defined by the following transfer function:

$$
Z_{S F}(s)=\frac{s^{2}\left(L_{S} C_{S F}+L_{S F} C_{S F}\right)+1}{s C_{S F}}
$$

As shown in the SPF frequency characteristics curve in Fig. 3, filter impedance is inductive and capacitive when higher and lower than resonant frequency, respectively. PPF offers high impedance in the grid frequency and low impedance in the harmonic frequency, thus preventing current fed-type harmonics from being transmitted to the grid.

The frequency characteristics of parallel passive filter is defined by the following transfer function:

$$
Z_{P F}(s)=H_{f}(s)=\frac{s L_{P F}}{s^{2} L_{P F} C_{P F}+1}
$$

The frequency characteristic curve of PPF is shown in Fig. 4. As shown in the graph, PPF offers high impedance

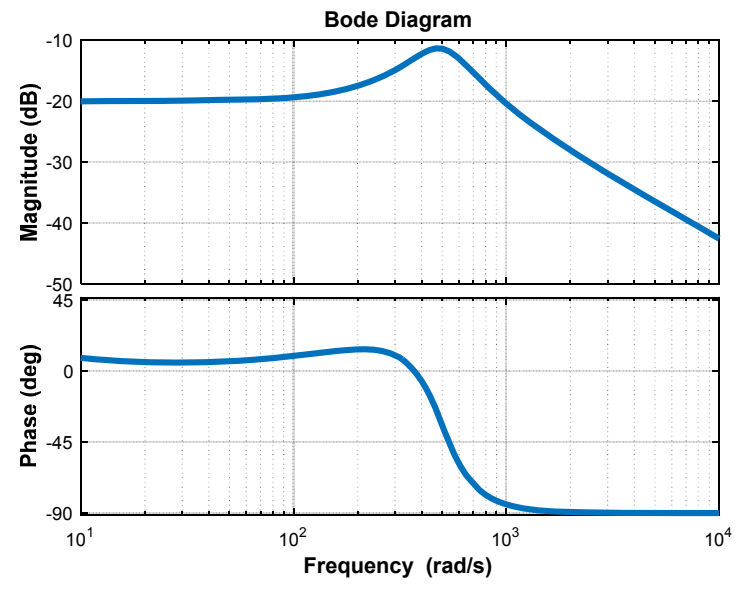

Fig. 5. Bode response of hybrid passive filter

in the fundamental frequency, and low impedance in all harmonic frequencies. Meanwhile, PPF impedance presents capacitive character when it is higher than resonant frequency. Because PPF presents high impedance in the grid frequency, the transmission of fundamental current component to the filter is prevented.

Output transfer function of hybrid passive filter is can be expressed as:

$$
H_{o}(s)=Z_{o}(s)=\frac{1}{\frac{1}{Z_{P F}(s)}+\frac{1}{Z_{S F}(s)+Z_{s}(s)}}
$$

And with some simple algebraic manipulations the transfer function becomes:

$$
Z(s)=\frac{Z_{P F}(s)\left[Z_{S F}(s)+Z_{s}(s)\right]}{Z_{P F}(s)+Z_{S F}(s)+Z_{s}(s)}
$$

The bode plot in Fig. 5 demonstrates the behavior of the hybrid passive filter configuration on the high-frequency harmonics for the output transfer function.

\section{Neuro-Fuzzy Controller Design}

NFCs are based on the principle that the functions of fuzzy logic controllers (FLC) are performed Artificial Neural Networks (ANN). NFCs have a non-linear structure and does not need the mathematical model of the system to be controlled. Therefore, NFCs are commonly used in nonlinear systems with parameter variation and uncertainty [20-21].

The fuzzy rules of a Sugeno-type NFC shown in Fig. 6 are defined as follows:

$$
R^{j} \text { : If } \mathrm{X}_{1} \text { is } A_{1}^{j} \text { and } \mathrm{X}_{2} \text { is } A_{2}^{j} \text {, Then } \mathrm{y} \text { is } \mathrm{w}_{\mathrm{j}}
$$




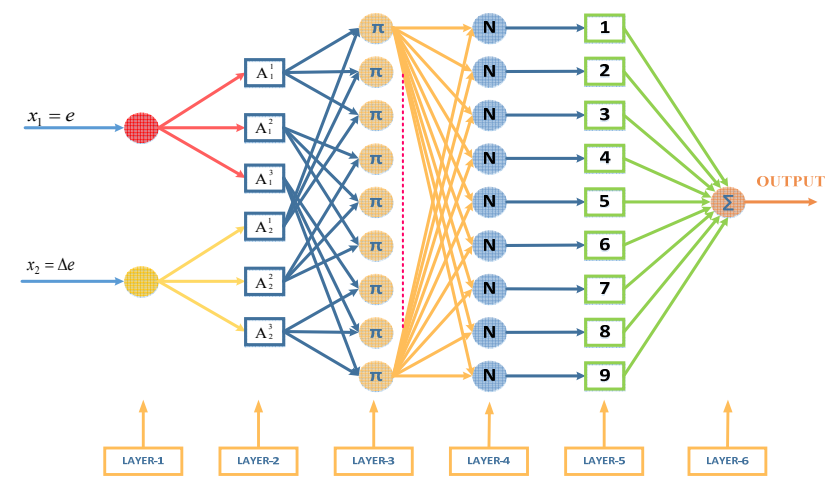

Fig. 6. Two-inputs Sugeno type NFC structure

In this formula, Here, $\mathrm{X}_{\mathrm{i}}$ is the input variable, $\mathrm{y}$ is the output variable, linguistic variables of prerequisites with $\mathrm{A}_{\mathrm{ij}} \mu_{\mathrm{Aij}}\left(\mathrm{X}_{\mathrm{i}}\right)$ membership function and $\mathrm{a}_{\mathrm{i}}^{\mathrm{j}} \in \mathrm{R}$ are the coefficients of linear $\mathrm{f}_{\mathrm{i}}=\left(\mathrm{x}_{1}, \mathrm{x}_{2}, \ldots, \mathrm{x}_{\mathrm{n}}\right)$ function. Therefore, the task of each layer between the input and output of NFC is defined as follows. NFC structure designed for DC bus voltage is shown in Fig. 6. A first order sugeno type NFC consists of two input, one output and six layers. The input variables of NFC are determined in the first layer. Input variables are the error and the change of error.

$$
\begin{gathered}
e(k)=V_{d c}^{*}-V_{d c} \\
\Delta e(k)=e(k)-e(k-1)
\end{gathered}
$$

Membership functions are performed in the second layer where membership function is replaced by the activation function of each artificial neuro cell. Five membership functions are determined for the error and the change of error [22]. The output of this layer is obtained as follows:

$$
n e t_{j}^{2}=-\frac{\left(x_{i}-m_{i j}\right)^{2}}{2\left(\sigma_{i j}\right)^{2}}, y_{j}^{2}=\exp \left(n e t_{j}^{2}\right)
$$

$\sigma_{\mathrm{ij}}$ and $\mathrm{m}_{\mathrm{ij}}$ represent the parameters of membership functions to be adapted. $X_{\mathrm{i}}$ represents the input of $\mathrm{i}$ th cell of second layer. Similar to fuzzy logic controller, the third layer of NFC consists of rule base and fuzzy rules are determined in this layer.

$$
n e t_{k}^{3}=\prod_{j} w_{j k}^{3} x_{j}^{3}, y_{k}^{3}=n e t_{k}^{3}
$$

Here, $\mathrm{X}_{\mathrm{j}}^{3}$ here represents the input of $\mathrm{j}$ th cell of third layer. The output of the system defined by using central clarification for Mamdani fuzzy logic:

$$
n e t_{0}^{4}=\sum_{k} w_{k o}^{4} y_{k}^{3}, y_{0}^{4}=\frac{n e t_{0}^{4}}{\sum_{k} y_{k}^{3}}
$$

Fourth layer is called normalization layer where the

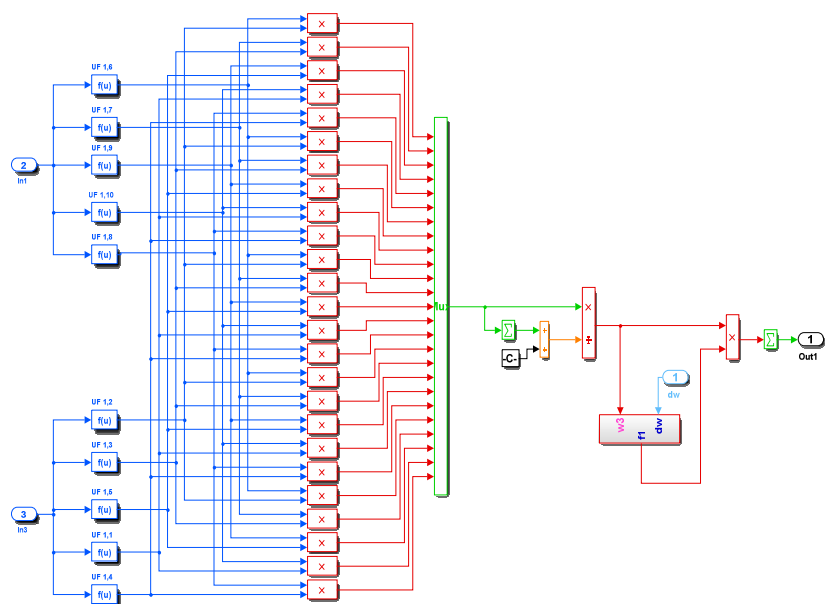

Fig. 7. Internal structure of NFC

accuracy of fuzzy rules are calculated. Fifth layer is called firing size of a rule.

The firing degree of normalized rules are multiplied by linear $\mathrm{f}$ function in this layer. This layer generates $\mathrm{d}$-axis current of PWM based rectifier. In order to update input and output parameters by using analog teaching method with back propagation algorithm, the squared error (E) which minimizes tracking error (e) is determined as follows [23-24]:

$$
E=\frac{1}{2} e^{2}
$$

The performance index for the parameters of membership functions in a PWM based rectifier can be derived as follows:

$$
\begin{aligned}
& \frac{\partial E}{\partial w_{k 0}}=-e \cdot \operatorname{sgn}\left(\frac{\Delta i_{d}}{\Delta y_{0}^{4}}\right) \frac{1}{\sum_{k} y_{k}^{3}} w_{k 0}^{4} \frac{\left(x_{i}-m_{i j}\right)}{\left(\sigma_{i j}\right)^{2}} y_{j}^{2} \\
& \frac{\partial E}{\partial \sigma_{i j}}=-e \cdot \operatorname{sgn}\left(\frac{\Delta i_{d}}{\Delta y_{0}^{4}}\right) \frac{1}{\sum_{k} y_{k}^{3}} w_{k 0}^{4} \frac{\left(x_{i}-m_{i j}\right)^{2}}{\left(\sigma_{i j}\right)^{3}} y_{j}^{2}
\end{aligned}
$$

The implementation of NFC used in the simulation studies via MATLAB/Simulink blocks is given in Fig. 7. Inputs of NFC are selected as the error and the change of error. Five membership functions are used for each input. In the NFC structure proposed in this study, precondition parameters of membership layer are trained in the simulation model. During simulation studies, results parameters are trained by using back propagation training algorithm. These parameters are adapted until the intended controlling performance is reached.

\section{Simulation Results}

The system was modelled via MATLAB R2014b 


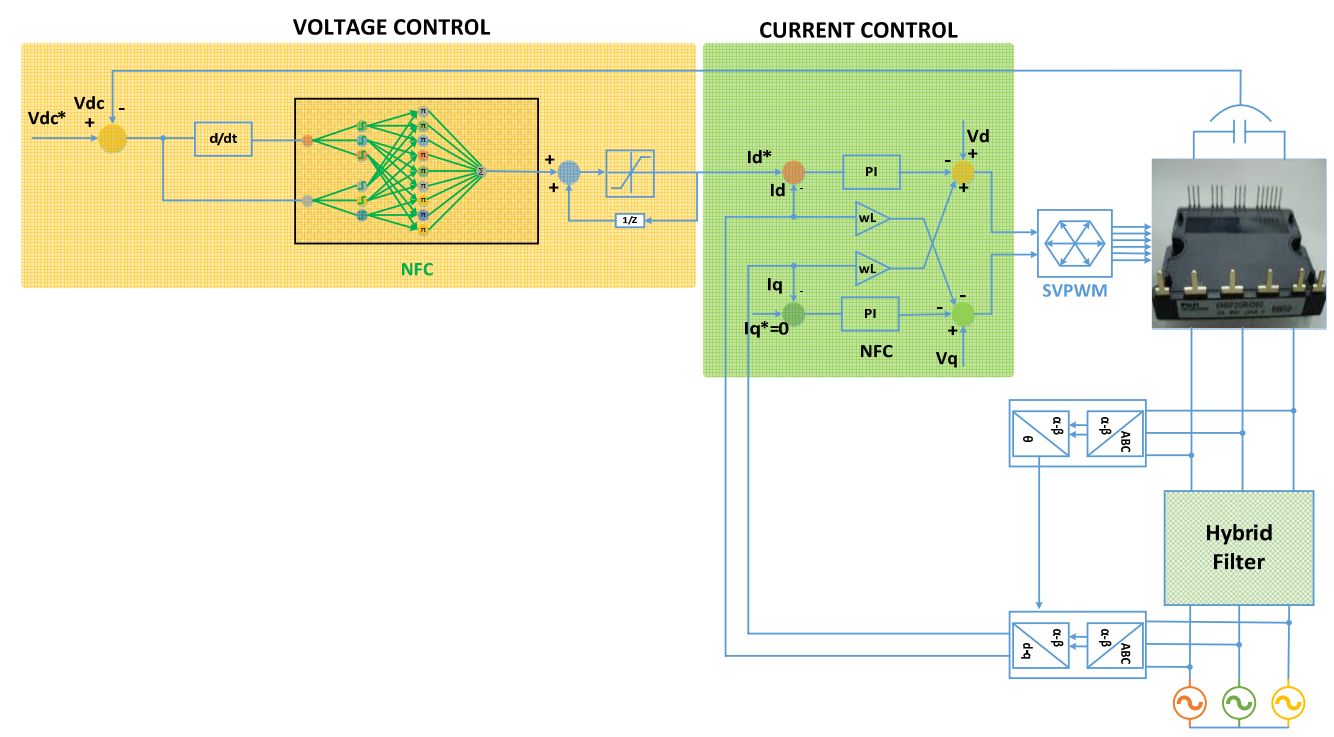

Fig. 8. Simulation model of the proposed PWM based rectifier with hybrid passive filter

Table 1. Power system parameters of simulation studies

\begin{tabular}{c|c|c}
\hline Line voltage & $V_{p-p}$ & $100 \mathrm{~V}$ \\
\hline Line frequency & $f$ & $50 \mathrm{~Hz}$ \\
\hline \multirow{2}{*}{ Line impedance } & $L_{s}$ & $0.3 \mathrm{mH}$ \\
\cline { 2 - 3 } & $R_{s}$ & $0.1 \Omega$ \\
\hline Sampling time & $T_{s}$ & $50 \mu \mathrm{s}$ \\
\hline
\end{tabular}

simulation program and SimPower System Toolbox in order to evaluate the performance of the proposed hybrid passive filter. Power system which was designed for simulation studies consists of three parts. These are an ideal and balanced power supply, PWM based rectifier used as the load, and hybrid passive filter system. The power system designed for simulation studies is shown in Fig. 8. Power system and simulation parameters are given in Table 1.

\subsection{Performance of unfiltered PWM rectifier}

The system operated for $1 \mathrm{~s}$ during all simulation studies. As can be seen by the DC bus voltage at the rectifier output shown in Fig. 9, it takes $0.5 \mathrm{~s}$ for PWM rectifier to start operating in a steady state under an unfiltered condition. Therefore, all graphs obtained during the simulation studies was analysed between 0.5 and $1 \mathrm{~s}$. PWM rectifier was operated in an unfiltered condition in order to better evaluate the impact of the rectifier on the power quality of the grid. PWM rectifier which was used as the load in the simulation study was controlled via vector control method, and DC bus voltage level at the output was adjusted at 200 $\mathrm{V}$. The value of DC bus output voltage under steady state conditions is shown in Fig. 9.

The harmonic spectrum of current and voltage belonging to a phase of current transmitted by the grid to the PWM based rectifier in an unfiltered condition are shown in Figs.

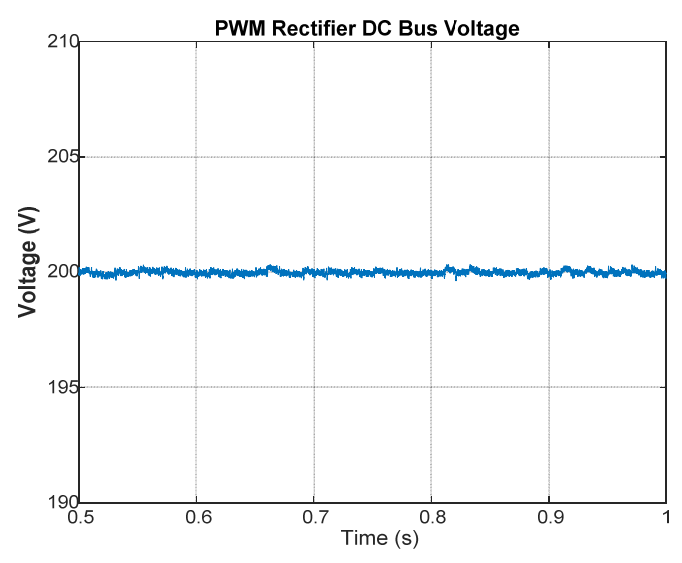

Fig. 9. DC bus voltage of PWM rectifier

10(a) and 10(b), respectively. When both harmonic spectrum are performed, it can be noted that dominant harmonics are between 80th and 150th harmonics. Changes in the total harmonic distortion of current and voltage following the start of steady state in an unfiltered condition are shown in Fig. 11 respectively. As shown in Fig. 11, total harmonic distortion of the current transmitted by the grid to the PWM rectifier varies between $38 \%$ and $45 \%$.

Similarly, total harmonic distortion of the voltage varies between $120 \%$ and $136 \%$. As shown in Fig. 9b, because of the fixed DC capacitor at its output, PWM rectifier often generated voltage fed-type harmonic.

\subsection{Performance of PWM rectifier with LCL filter}

Configuration of PWM rectifier with LCL filter is shown in Fig. 12. LCL filter consists of $L_{1}, L_{2}, C_{d}$ and $R_{d}$. In this operation, LCL filter configuration was proposed in order to evaluation performance of proposed filter structure and added to the structure of the rectifier. Parameters of 


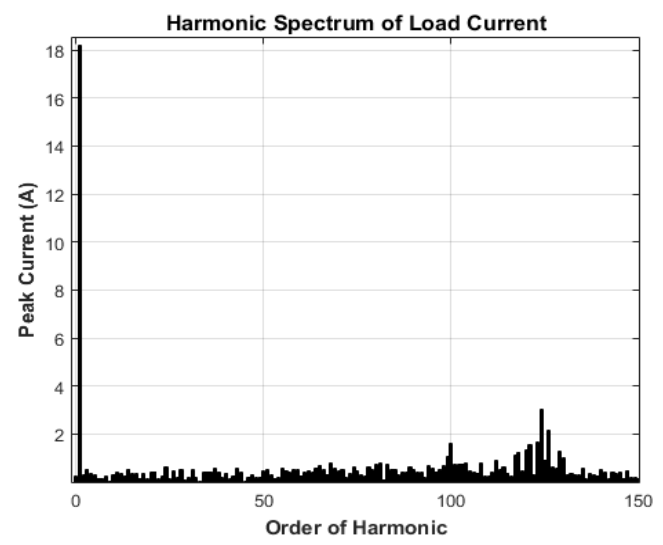

(a)

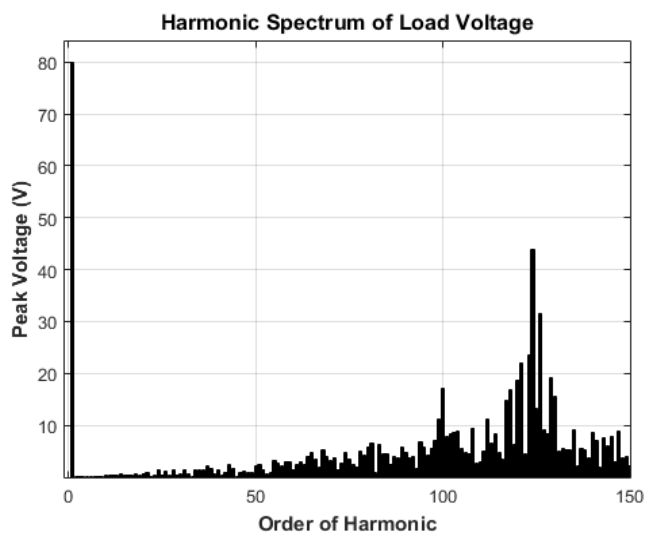

(b)

Fig. 10. Harmonic spectrum of grid current and voltage in an unfiltered condition

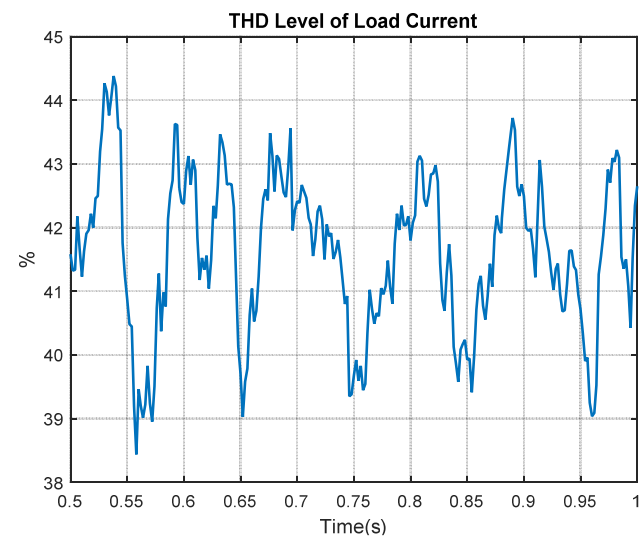

(a)

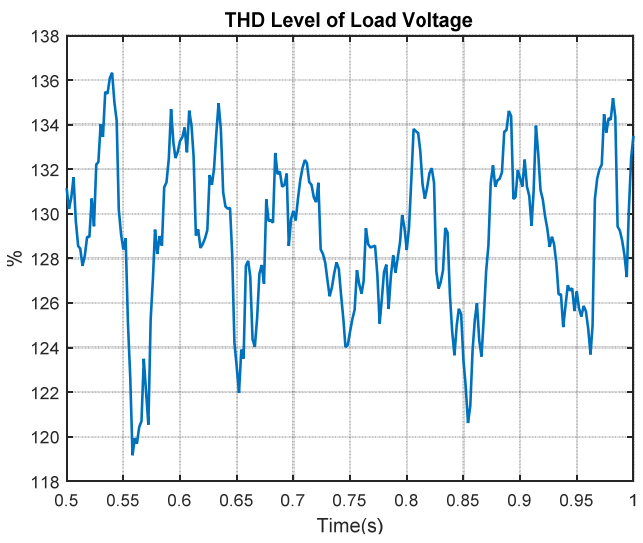

(b)

Fig. 11. Changes in the total harmonic distortion of grid current and grid voltage

Table 2. Parameters of LCL filter

\begin{tabular}{c|c}
\hline Parameter & Value \\
\hline $\mathrm{C}_{\mathrm{d}}$ & $4 \mu \mathrm{F}$ \\
\hline $\mathrm{L}_{1}$ & $2.1 \mathrm{mH}$ \\
\hline $\mathrm{L}_{2}$ & $3.5 \mathrm{mH}$ \\
\hline $\mathrm{R}_{\mathrm{d}}$ & $10 \Omega$ \\
\hline
\end{tabular}

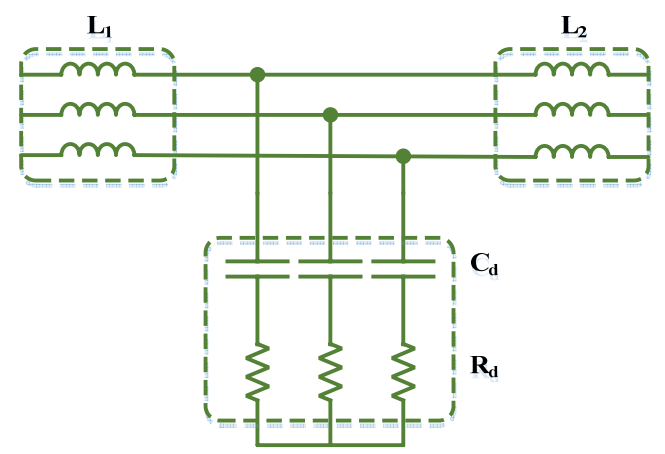

Fig. 12. Configuration of LCL filter structure

LCL filter are given Table 2.

Harmonic spectrum of the current and voltage obtained
Table 3. Parameters of hybrid passive filter

\begin{tabular}{c|c|c}
\hline SPF Capacitor & $\mathrm{C}_{\mathrm{SF}}$ & $330 \mu \mathrm{F}$ \\
\hline SPF Reactor & $\mathrm{L}_{\mathrm{SF}}$ & $30.7 \mathrm{mH}$ \\
\hline PPF Capacitor & $\mathrm{C}_{\mathrm{PF}}$ & $680 \mu \mathrm{F}$ \\
\hline PPF Reactor & $\mathrm{L}_{\mathrm{PF}}$ & $14.9 \mathrm{mH}$ \\
\hline
\end{tabular}

from LCL filter based PWM rectifier are given in Figs. 13(a) and 13(b), respectively. According to harmonic spectrum graphs, it has been seen that LCL filter has good performance in terms of mitigating harmonics in grid current and voltage.

\subsection{Performance of PWM rectifier with proposed filter}

In this operation, hybrid passive filter configuration was proposed by taking unfiltered operation conditions into consideration and added to the structure of the rectifier. Parameters of the designed filter are given Table 3.

Harmonic spectrum of the current and voltage measured by the grid following the addition of the filter to the system are given in Fig. 14. As harmonic spectrum graphs also 


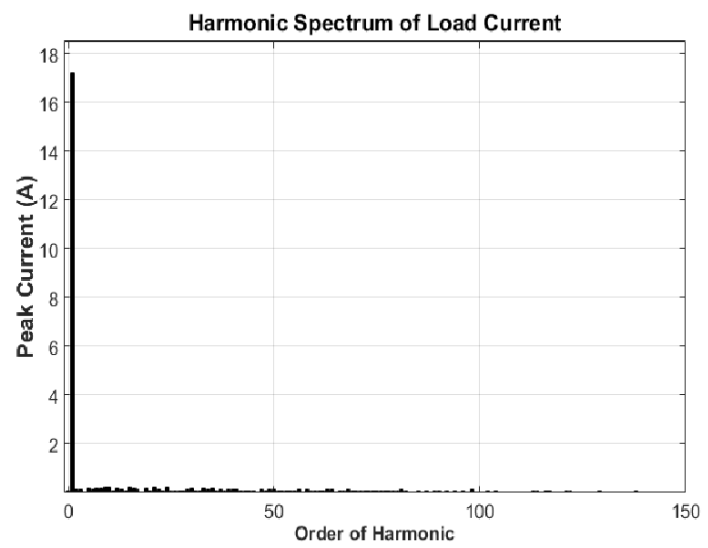

(a)

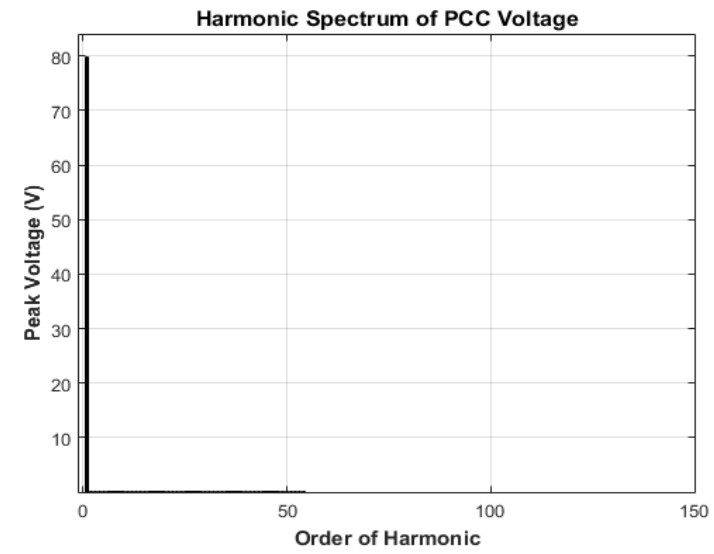

(b)

Fig. 13. Harmonic spectrum of the grid current and voltage under LCL filter operation

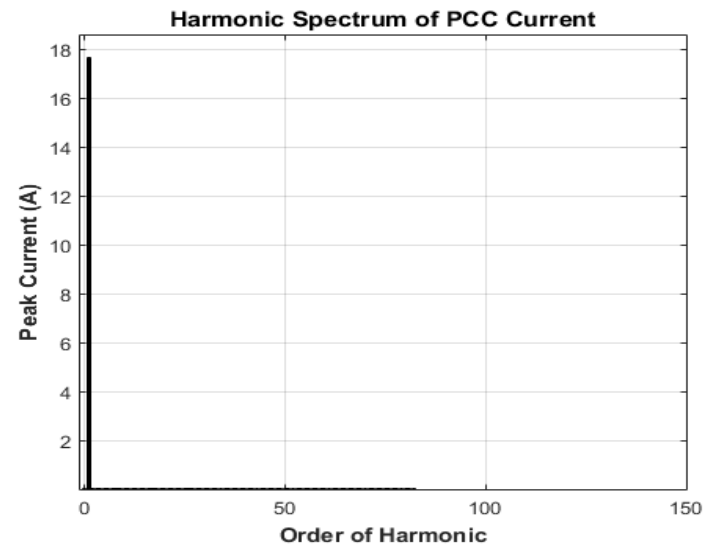

(a)

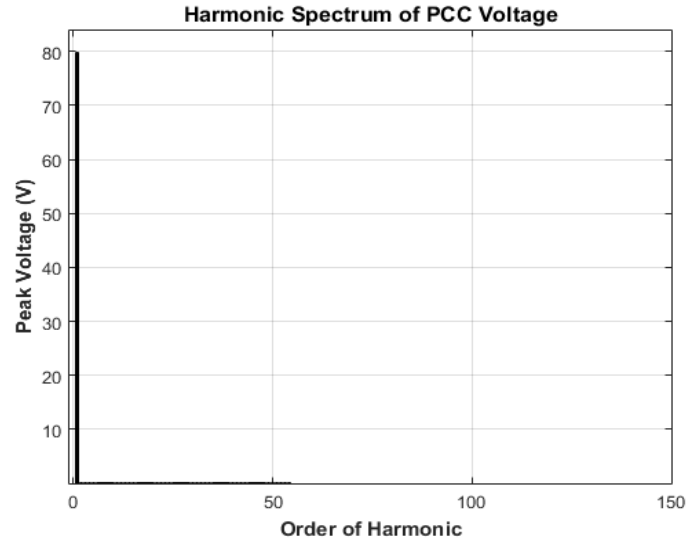

(b)

Fig. 14. Harmonic spectrum of the grid current and voltage under proposed filter operation

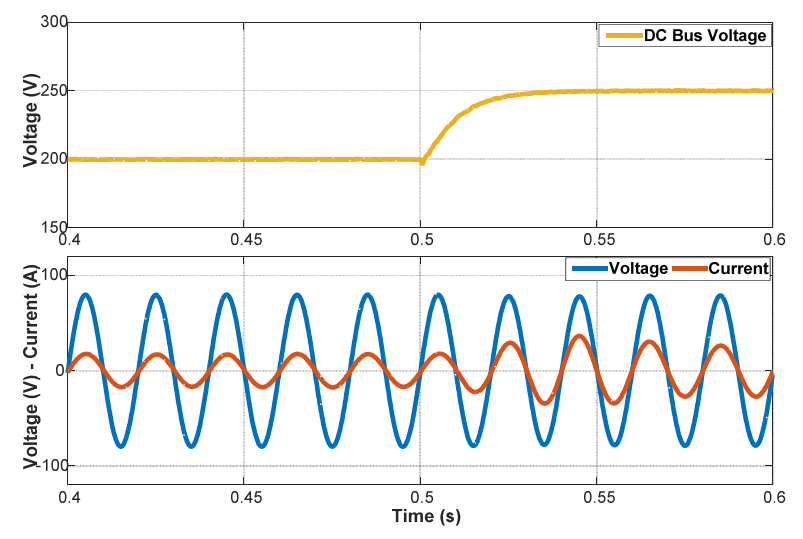

Fig. 15. Waveforms of current-voltage and DC bus voltage during changes in DC bus voltage

demonstrate, harmonics caused by the rectifier following the addition of the filter to the rectifier was filtered by the proposed filter, which prevented harmonics from reaching the grid.

The success of designed filter with PWM rectifier can be analysed by analyzing DC bus voltage and waveforms of

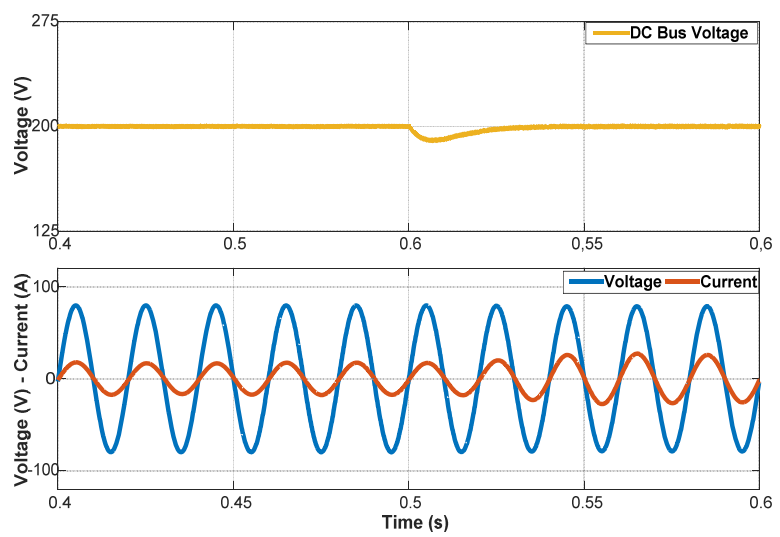

Fig. 16. Waveforms of current-voltage and DC bus voltage during changes in load

AC current and voltage together. When the graphs are analysed, it can be noted that DC bus voltage, between 0.4 and $0.6 \mathrm{~s}$, is at the level of $200 \mathrm{~V}$ which was taken as a reference value by the PWM based rectifier, and that waveforms of the current transmitted by the grid to the rectifier and grid voltage were sinusoidal. In addition, as 

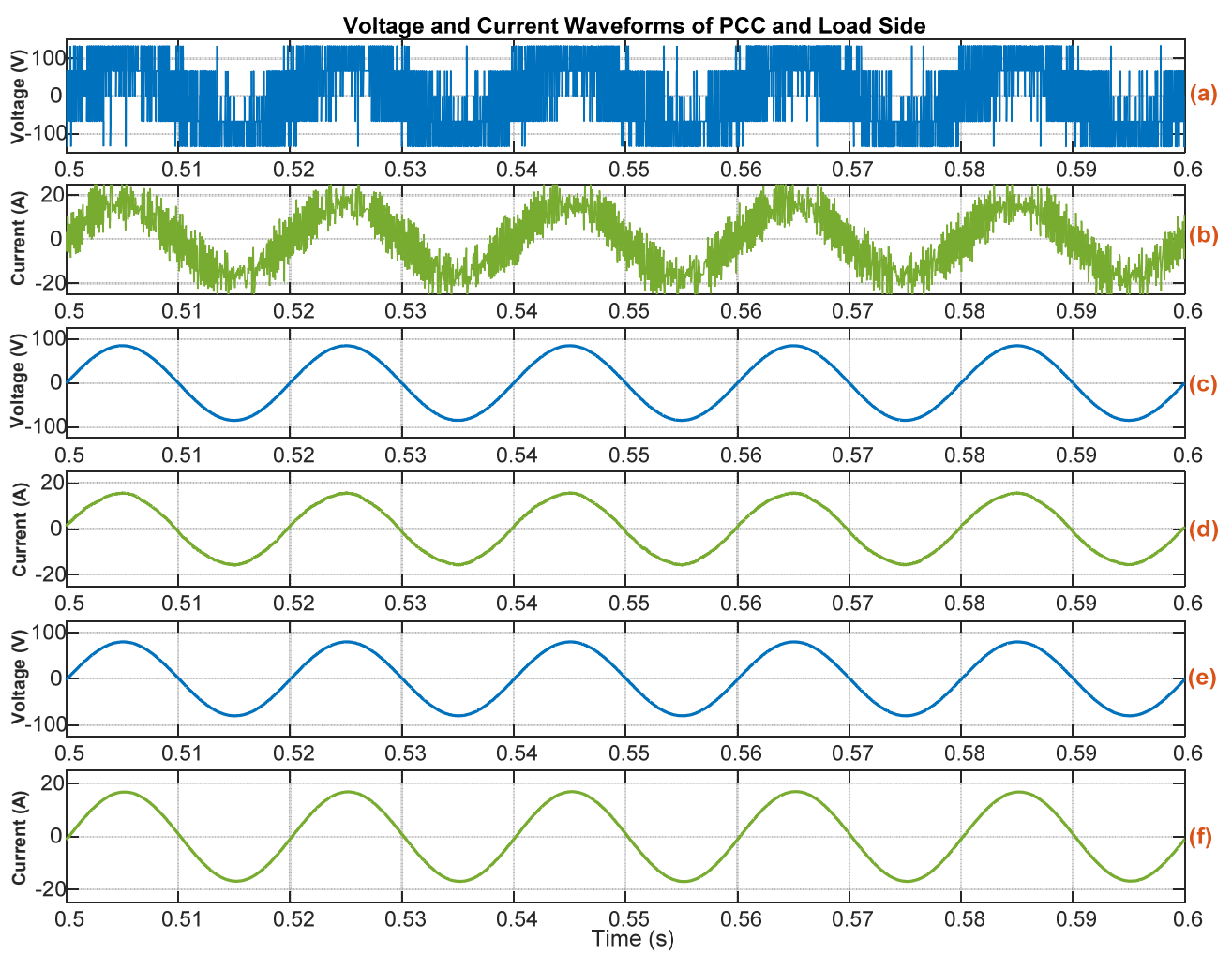

Fig. 17. Waveforms of the grid voltage and current (a-b) in unfiltered condition (c-d) in LCL filter condition, (e-f) in proposed filter condition

shown by waveforms of current and voltage, power factor of the PWM based rectifier is very close to 1 . The performance of hybrid filter PWM rectifier with NFC under different voltage and loads was analysed, too. As shown in Fig. 15, DC bus voltage was first adjusted at $200 \mathrm{~V}$, and later, it was increased to $250 \mathrm{~V}$. NFC, which has a robust structure, rapidly followed DC bus voltage without overshoot. As a result, the current value has increased from 17.25 Ampere to 26.2 Ampere. No distortion was observed in the form of the current, and current-voltage is in the same phase. The dynamic performance of hybrid filter PWM rectifier with NFC against load change is analysed in Fig. 16. DC bus voltage is $200 \mathrm{~V}$. The existing load in the system was changed in the 0.5 th $\mathrm{s}$. As a result, DC voltage decreased to $195.1 \mathrm{~V}$, and it rapidly reached DC bus voltage in $0.53 \mathrm{~s}$.

Waveforms of current and voltage under filtered and unfiltered conditions were analysed in order to better evaluate the success of the proposed filter. We waited until the system started to operate in a steady state for this analysis. Graphs are shown at five periods of $0.1 \mathrm{~s}$ in order to closely analyze waveforms of current and voltage. Waveforms of current and voltage in filtered and unfiltered conditions are shown in Fig. 17. All measurements were performed in the measurement bus on the grid. Waveforms of the voltage and current in unfiltered condition are shown in Figs. 17(a) and 17(b), respectively. Waveform of the grid and waveform of the current transmitted by the grid voltage in LCL filter condition are shown in Figs. 17(c) and $17 \mathrm{~d}$, respectively. Similarly, Figs. 17(e) and 17f show the waveform of the grid and waveform of the current transmitted by the grid voltage hybrid passive filter condition. As shown in Fig. 17, the hybrid passive filter designed in the present study eliminated completely the harmonics caused by PWM rectifier.

\section{Conclusions}

In this work, the PWM rectifiers which possess characteristics such as high power factor, sinusoidal input current and low harmonic distortion are proposed permanent magnet synchronous generator based wind energy conversion systems. In general, L-type filters are used in these rectifiers. Even though this filter is successful, it cannot completely compensate harmonic distortion. In the present study, hybrid passive filter was proposed instead of $\mathrm{L}$ filter which has been very commonly used for conventional PWM rectifiers in the literature. Also, LCL filter is designed to show clearly the performance of the proposed filter. The series filter within hybrid passive filter compensates voltage fed-type harmonics while the parallel filter compensates current fed-type harmonics. Harmonic distortions of PWM rectifier observed under filtered, LCL filter and unfiltered conditions, and power factor values are given in Table 4. It demonstrates that total harmonic 
Table 4. Performance Results of Hybrid Passive Filter

\begin{tabular}{c|c|c|c}
\hline & $\begin{array}{c}\text { Unfiltered } \\
\text { operation }\end{array}$ & $\begin{array}{c}\text { LCL } \\
\text { Filter }\end{array}$ & $\begin{array}{c}\text { Proposed } \\
\text { filter }\end{array}$ \\
\hline $\mathrm{THD}_{\mathrm{V}}$ & $133.49 \%$ & $0.05 \%$ & $0.01 \%$ \\
\hline $\mathrm{THD}_{\mathrm{I}}$ & $42.65 \%$ & $1.48 \%$ & $0.18 \%$ \\
\hline Cos $\varphi_{\text {fundamental }}$ & 1.00 & 1.00 & 1.00 \\
\hline True power factor & 0.55 & 1.00 & 1.00 \\
\hline
\end{tabular}

distortion of the voltage during unfiltered condition was reduced from $133.49 \%$ to $0.01 \%$ by the proposed filter and from $133.49 \%$ to $0.05 \%$ by the LCL filter in the present study. While total harmonic distortion of the current under unfiltered condition was measured as $42.65 \%$, total harmonic distortion of the current was reduced to $0.18 \%$ and $1.48 \%$ after the proposed filter and LCL filter were added. No phase differences exist between main components of current and voltage under filtered, LCL filter and unfiltered conditions. However, true power factor was calculated as 0.55 in unfiltered condition due to the harmonic impact, and true power factor increased to 1.00 after hybrid passive filter and LCL filter were added to PWM rectifier. It is well-known that PI controllers are used in PWM rectifiers due to their simple structure. However, in the present study, the dynamic structure of PWM rectifier was improved against changing conditions thanks to the designed NFC, which is robust and non-linear, and it was supported by simulation studies as well.

\section{References}

[1] A. Urtasun, P. Sanchis, I. S. Martín, J. López and L. Marroyo, "Modeling of small wind turbines based on PMSG with diode bridge for sensorless maximum power tracking," Renewable Energy, vol. 55, pp. 138-149, 2013.

[2] A. Rolan, A. Luna, G. Vazquez and D. Azevedo, "Modeling of a variable speed wind turbine with a permanent magnet synchronous generator," in Proc. IEEE International Symposium on Industrial Electronics, 2009, pp. 734-739.

[3] H. M. Farh and A. M. Eltamaly, "Fuzzy logic control of wind energy conversion system," Journal of Renewable and Sustainable Energy, vol. 5, no. 2, 2013.

[4] R. S. Bajpai, M. Goyal and R. Gupta, "Modeling and control of variable speed wind turbine using laboratory simulator," Journal of Renewable and Sustainable Energy, vol. 7, 2015.

[5] Y. Snal, W. Mzc and A. Mohamed, "Implementation of different passive filter designs for harmonic mitigation: Power and Energy Conference," 2004, pp. 229-34.

[6] A. Hamadi, S. Rahmani and K. Al-Haddad, "A Hybrid Passive Filter Configuration for VAR Control and Harmonic Compensation," IEEE Transactions on Industrial Electronics, vol. 57, no. 7, pp. 2419-2433, 2010.

[7] M. Sekkeli and N. Tarkan, "Development of a novel method for optimal use of a newly designed reactive power control relay," International Journal of Electrical Power \& Energy Systems, vol. 44, pp. 736-742, 2013.

[8] S. Rahmani, A. Hamadi and K. Al-Haddad, "New Three Phase Hybrid Passive Filter to Dampen Resonances and Compensate Harmonics and Reactive Power for Any Type of Load under Distorted Source Conditions," Power Electronics Specialists Conference (PESC), 2007, pp. 2594-2599.

[9] P. Thirumoorthi and N. Yadaiah, "Design of current source hybrid power filter for harmonic current compensation," Simulation Modelling Practice and Theory, vol. 52, pp. 78-91, 2015.

[10] V. Dzhankhotov and J. Pyrhonen, "Passive LC Filter Design Considerations for Motor Applications," IEEE Transactions on Industrial Electronics, vol. 60, no. 10, pp. 4253-4259, 2013.

[11] S.N.A.L Yousif, M.Z.C. Wanik and A. Mohamed, "Implementation of different passive filter designs for harmonic mitigation," Power and Energy Conference, 2004, pp. 229-34.

[12] G. J. Wakileh, Power system harmonics fundamentals, analysis and filter design, Springer Verlag Press, New York, 2001.

[13] S. Chen and G. Joos, "Analysis and Comparison of Passive \& Active Harmonic Suppression Filters in Distribution Systems," Canadian Conference on Electrical and Computer Engineering, 2000, pp. 615619.

[14] L. Shuhui, J. Ishan, S. Raed and F. Xingang, "Directcurrent Vector Control of Three-phase Grid-connected Converter with L, LC, and LCL Filters," Electric Power Components and Systems, vol. 43, no.14, pp. 1644-1655, 2015.

[15] Z. Lidong, L. Harnefors and H.P. Nee, "Power synchronization control of grid connected voltage source converters," IEEE Trans. Power Syst., vol. 25, pp. 809-820. 2010.

[16] B. Singh, B.N. Singh, A. Chandra, K. Al-Haddad, A. Pandey, and D.P. Kothari "A Review of Three-Phase Improved Power Quality AC-DC Converters," IEEE Transactions on Industrial Electronics, vol. 51, pp. 641-660, 2004.

[17] V. Blasko and V. Kaura, "A New Mathematical Model and Control of a Three-Phase AC-DC Voltage Source Converter," IEEE Transaction on Power Electronics, vol. 12, pp. 116-123, 1997.

[18] C. Cecati, A. Dell'Aquila, M. Liserre and A. Ometto "A fuzzy-logic based controller for active rectifier," IEEE Trans. Ind. Appl., vol. 39, no. 1, pp. 105-112, 2003.

[19] J. Dannehl, C. Wessels, and F. Fuchs, "Limitations of 
voltage oriented PI current control of grid-connected PWM rectifiers with LCL filters," IEEE Transactions on Industrial Electronics, vol. 56, no. 2, pp. 380-388, 2009.

[20] M. Gokbulut, B. Dandil, and C. Bal, "Development and Implementation of Fuzzy-Neural Network Controller for Brushless DC Motors," Intelligent Automation and Soft Computing, vol. 13, no. 4, pp. 423-435, 2007.

[21] J.S.R. Jang, C.T. Sun, and E. Mizutani, Neuro-Fuzzy and Soft Computing, Prentice Hall, USA, 1997.

[22] R. Coteli, E. Deniz, B. Dandil, S. Tuncer and F. Ata, "Phase Angle Control of Three Level Inverter Based D-STATCOM Using Neuro-Fuzzy Controller," Advances in Electrical and Computer Engineering, vol. 12, no. 1, pp. 77-84, 2012.

[23] B. Dandil, "Fuzzy Neural Network IP Controller For Robust Position Control of Induction Motor Drive," Expert Systems with Applications, vol. 36, pp. 45284534, 2009.

[24] M. Mohaddes, A. M. Gole, and P.G. Mclaren, "A Neural Network Controlled Optimal Pulse-Width Modulated STATCOM," IEEE Trans. Power Deliv., vol. 14, no. 2, pp. 481-488, 1999.

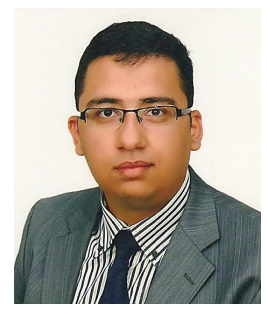

O. Fatih Kececioglu received B.Sc., M.Sc. degrees in electrical and electronics engineering from Kahramanmaras Sutcu Imam University (KSU), Turkey, in 2010, 2012, respectively. He is currently working towards to the Ph.D. degree. Since 2011, he has been with Electrical and Electronics Engineering Department, KSU as a research assistant. His research interests include power quality, power electronics, harmonic mitigation, harmonic filter and renewable energy systems.

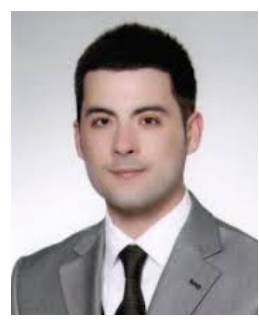

Hakan Acikgoz received the B.Sc. and M.Sc. degrees from Firat University, Elazıg, Turkey, in 2008 and 2010, respectively. He is currently working towards to the Ph.D degree in Electrical and Electronic Engineering and he is a lecturer at Kilis 7 Aralik University. His research interests are power electronic converters, electronic power transformers, artificial neural networks and fuzzy logic controller.

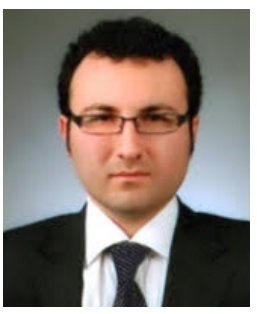

Ceyhun Yildiz received the B.Sc. and M.Sc. degrees from Mustafa Kemal and K.Maras Sutcu Imam University, Turkey, in 2003 and 2008, respectively. $\mathrm{He}$ is currently working towards to the $\mathrm{Ph} . \mathrm{D}$ degree in Electrical and Electronic Engineering and $\mathrm{He}$ is a lecturer at K.Maras Sutcu Imam University. His research interests are electrical machine drivers, renewable power and artificial intelligence.

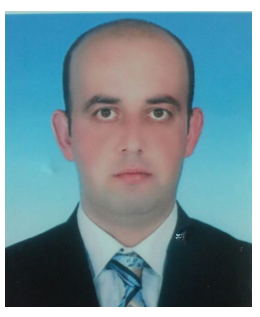

Ahmet Gani received the B.Sc. and M.Sc. degrees from Erciyes and K. Maras Sutcu Imam University, Turkey, in 2011 and 2014, respectively. He is currently working towards to the Ph.D degree in Electrical and Electronic Engineering and he is a specialist at K.Maras Sutcu Imam University. His research interests are electrical machine drivers, renewable power and fuzzy logic controller.

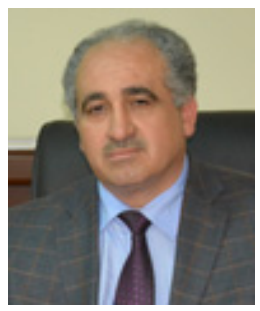

Mustafa Sekkeli received B.Sc., M.Sc. and $\mathrm{Ph} . \mathrm{D}$ degrees in electrical and electronics engineering from Istanbul Technical University, 1986, 1989 and 2005 respectively. Between 1999 and 2007, He worked as a lecturer in Electrical and Electronics Department, Kahramanmaras Sutcu Imam University. Since 2007, he has been with Electrical and Electronics Engineering Department, Kahramanmaras Sutcu Imam University as Assoc. Prof. Dr. His research interests include power quality, power electronics, electrical machine control, reactive power compensation, and renewable energy systems. 